\title{
Effective Resistance to Wheat Stripe Rust in a Region with High Disease Pressure
}

B. Bai, State Key Laboratory of Crop Stress Biology in Arid Areas/College of Agronomy, Northwest A \& F University, Yangling 712100, Shaanxi, China, and Wheat Research Institute, Gansu Academy of Agricultural Sciences, 1 Nongkeyuanxincun, Lanzhou 730070, China; J. Y. Du, Q. L. Lu, C. Y. He, L. J. Zhang, and G. Zhou, Wheat Research Institute, Gansu Academy of Agricultural Sciences; X. C. Xia, Institute of Crop Science, National Wheat Improvement Center, Chinese Academy of Agricultural Sciences (CAAS), 12 Zhongguancun South Street, Beijing 100081; Z. H. He, Institute of Crop Science, National Wheat Improvement Center, CAAS, Beijing, and International Maize and Wheat Improvement Center (CIMMYT), CIMMYT China Office, c/o CAAS, Beijing; and C. S. Wang, State Key Laboratory of Crop Stress Biology in Arid Areas/College of Agronomy, Shaanxi

\begin{abstract}
Bai, B., Du, J. Y., Lu, Q. L., He, C. Y., Zhang, L. J., Zhou, G., Xia, X. C., He, Z. H., and Wang, C. S. 2014. Effective resistance to wheat stripe rust in a region with high disease pressure. Plant Dis. 98:891-897.

Stripe rust is a major fungal disease of wheat. It frequently becomes epidemic in southeastern Gansu province, a stripe rust hot spot in China. Evaluations of wheat germplasm response are crucial for developing cultivars to control the disease. In total, 57 wheat cultivars and lines from Europe and other countries, comprising 36 cultivars with documented stripe rust resistance genes and 21 with unknown genes, were tested annually with multiple races of Puccinia striiformis $\mathrm{f}$. sp. tritici in the field at Tianshui in Gansu province from 1993 to 2013. Seven wheat lines were highly resistant, with infection type (IT) 0 during the entire period; 16 were moderately resistant (IT 0;-2); and 26 were moderately susceptible (IT $0 ;-4$ ), with low maximum disease

severity compared with the susceptible control Huixianhong. 'Strampelli' and 'Libellula', with three and five quantitative trait loci, respectively, for stripe rust resistance have displayed durable resistance in this region for four decades. Ten cultivars, including 'Lantian 15', 'Lantian 26', and 'Lantian 31', with stripe rust resistance derived from European lines, were developed in our breeding program and have made a significant impact on controlling stripe rust in southeastern Gansu. Breeding resistant cultivars with multiple adult-plant resistance genes seems to be a promising strategy in wheat breeding for managing stripe rust in this region and other hot spots.
\end{abstract}

Wheat stripe rust (or yellow rust [YR]), caused by Puccinia striiformis f. tritici Erikss., is one of the most destructive foliar diseases of wheat globally. China has one of the largest epidemic regions for $\mathrm{YR}$ in the world, and epidemics of the disease occur frequently in the autumn-planted wheat-growing regions of northwestern and southwestern China. From 2004 to 2009, YR occurred on about 4.2 million ha each year and caused serious damage to wheat production in China $(13,18)$. Recently, YR was particularly prevalent in Sichuan, Chongqing, Shaanxi, and Gansu provinces; Shiyan and Xiangfan regions of Hubei province; and the Xinyang and Nanyang regions of Henan province.

Resistance breeding is an effective, economic, and environmentally friendly approach to control YR (6). However, many wheat cultivars have become susceptible to YR due to changes in the pathogen population, and even some new breeding lines became susceptible before being officially released into production. Many Chinese wheat cultivars with $\operatorname{Yr} 9$ (1B.1R translocation) became susceptible after the spread of $P$. striiformis $\mathrm{f}$. tritici race CYR29 during the 1990s, and then 'Fan 6' and its derivatives became susceptible in 2002 (5). More than 50 genes for resistance to YR are formally named in wheat and most are assigned to various chromosomal regions (25). However, the majority of these genes are either not effective in China or were

Corresponding authors: C. S. Wang, E-mail: wangcs2008@126.com; and Z. H. He, E-mail: zhhecaas@163.com

* The $\boldsymbol{e}$-Xtra logo stands for "electronic extra" and indicates that a supplementary table, or appendix, is available online.

Accepted for publication 19 November 2013.

http://dx.doi.org/10.1094/PDIS-09-13-0909-RE

(C) 2014 The American Phytopathological Society overcome by the pathogen populations at different times. Only a few named major genes (such as $\operatorname{Yr} 5$ and $\mathrm{Yr} 15$, and some temporarily designated genes, such as $Y r G a b y$ ) and several adult-plant resistance (APR) genes (such as $Y r 18$, Yr29, and Yr46) are effective in limiting the size of the Chinese $P$. striiformis $\mathrm{f}$. tritici population. Thus, there is an ongoing need to identify and develop new resistant materials and to understand the resistance genes present in wheat cultivars and lines. Considerable work has been done in a number of countries, including China, on the basis of YR resistance in spring wheat germplasm but relatively little has been reported on durable resistance in winter wheat from European countries.

Southeastern Gansu, especially Tianshui and Longnan in China, is a well documented hot spot for YR $(5,19,33,36)$. In these areas, $P$. striiformis f. tritici can complete a year-round uredinial cycle, because about 250,000 ha of wheat are grown in areas that extend from lowland valleys at $800 \mathrm{~m}$ above sea leave (asl) to highland terraces at 2,400 $\mathrm{m}$ asl, providing a "green bridge" for $P$. striiformis $\mathrm{f}$. tritici that migrates throughout the year from late-maturing highland areas to early-sown wheat fields in the lowlands $(5,19,36)$. Several Berberis spp. (barberry) occur in the region and, following the recent discovery that barberry is a potential alternate host for $P$. striiformis f. tritici $(14,38)$, the possibility of sexual reproduction and genetic recombination contributing to the apparently high level of pathogen variability in the region is only now being appreciated and studied (38). This continuous epidemic recycling maintains large pathogen populations and high pathogenic variability that leads to frequent "break-downs" in resistance and, thus, an urgency to broaden the genetic basis of resistance in wheat cultivars used in the region.

The objective of this study was to report on long-term assessments of European wheat germplasm in southeastern Gansu since 1993, and to identify germplasm with effective resistance to YR in a region with high disease pressure, several of which have been used in our breeding program. 


\section{Materials and Methods}

Wheat germplasm. Fifty-seven wheat cultivars and lines from Europe and other countries were evaluated annually for YR response in the field at Tianshui of southeastern Gansu from 1993 to 2013. All cultivars and lines were originally provided by the International Maize and Wheat Improvement Center and Chinese Academy of Agricultural Science. The YR resistance genes, origin, and pedigrees of cultivars or lines are listed in Table 1. Although many of the cultivars and lines were known or postulated to possess welldocumented resistance genes based on classical seedling tests, it was not known whether those genes or other genes for seedling (all-stage) resistance and APR contributed to the observed responses at Tianshui.

$P$. striiformis f. tritici races. The trial comprised both inoculated and naturally infected nurseries. The Chinese $P$. striiformis f. tritici races used in artificial inoculations differed over time with changes in the local populations. The key races included CYR29 (the first race that became epidemic on cultivars with $\operatorname{Yr} 9$ in the 1990s), CYR30 (virulent on 'Hybrid 46' with Yr3b and Yr4b, Fan 6 and its derivatives such as 'Miannong 4', 'Mianyang', and several lines in the 'Chuanmai' series in 1991), CYR31 (with virulences similar to CYR30, appearing in 1993), CYR32 (with the widest virulence spectrum combining the virulences of CYR31 with virulence for

Table 1. Pedigrees and origin of wheat cultivars and lines used in this study ${ }^{\mathrm{a}}$

\begin{tabular}{|c|c|c|c|}
\hline Cultivar/line & Yr gene $^{\text {b }}$ & Pedigree & Origin \\
\hline Aquila I & I & San Giovanni/Damiano & Italy \\
\hline Atou & Yr3a, Yr4a, Yrl6 & Cappelle Desprez/Garnet & France \\
\hline Bouquet & Yr3a, Yr4a, Yr14, Yr16 & 2-7, Versailles/Cappelle Desprez//Cappelle Desprez & France \\
\hline Cappelle Desprez & Yr3a, Yr4a, Yr16 & Vilmorin 27/Hybride Du Joncquois & France \\
\hline Carstens V & $\operatorname{Yr} 32(\mathrm{YrCV})$ & Carstens III/Dickkopf//Dickkopf/Criewener 104 & Germany \\
\hline Champlein & Yr3a, Yr4a, Yr16 & Yga Blondeau/Tadepi & France \\
\hline Cik Vee & 1 & 1 & / \\
\hline Compair & $\operatorname{Yr} 8, \operatorname{Yr} 19$ & Chinese Spring/Ae.Co & United Kingdom \\
\hline C591 & $\operatorname{YrC591}$ & PB Type 8B/PB Type 9 & India \\
\hline Dippes Triumph & Yr15 & Derenburger Silber/Erbachshofer Braun & Germany \\
\hline Elite Le Peuple & $Y r 2, \mathrm{DR}$ & Bellevue/Hybride De Bersee & France \\
\hline Fenman & $Y r 1, Y r 2$ & TJB 268/175/Hobbit 'Sib' & United Kingdom \\
\hline Flanders & $\operatorname{Yrl}, Y r 3 a, Y r 4 a, Y r 16$ & Champlein/FD 2816-348 & France \\
\hline Flinor & $\mathrm{DR}$ & Elite Le-Peuple/Poncheau & France \\
\hline FR 81-1 & 1 & I & France \\
\hline Gaby & YrGaby & Koga/Fylby & Belgium \\
\hline German 2 & / & 1 & Germany \\
\hline German 8661 & I & I & Germany \\
\hline Heines VII & Yr2, Yr25, YrHVII & Hybrid A Courte Palle/Kronen, Swe & Germany \\
\hline Heines Kolben & $\operatorname{Yr} 2, \mathrm{Yr} 6$ & 1 & Germany \\
\hline Hobbit & Yr3, Yr4, Yr14, YrHVII & Professeur Marchal//Marne-Desprez/VG9144/3 /// TJB 16* & United Kingdom \\
\hline Holdfast & DR & Yeoman/White Fife & United Kingdom \\
\hline Hybrid 46 & Yr3b, $\mathrm{Yr} 4 b, \mathrm{YrH} 46$ & Benoist 40/Yeoman & United Kingdom \\
\hline Ibis & $Y r 1, Y r 2$, APR QTL & Merlin//Heines VII/Heines 2167 & Germany \\
\hline Joss Cambier & $\operatorname{Yr} 2, \operatorname{Yr} 11$ & Heines VII/Tadepi//Cappelle Desprez & France \\
\hline Jubilar & I & Pfeuffers Schernauer//Taca/Derenburger Silber & Germany \\
\hline Libellula & Yr18 + APR QTL & Tevere/Giuliari(1482-54-3)//San Pastore & Italy \\
\hline Little Joss & DR & Squareheads Master/Ghirka & United Kingdom \\
\hline Longbow & $\operatorname{Yr} 1, \operatorname{Yr} 2, \operatorname{Yr} 6, \operatorname{Yr} 9, \operatorname{Yr} 13$ & TJB 268-175/Hobbit & United Kingdom \\
\hline Lperfer & / & l & / $100-0$ \\
\hline Maris Huntsman & $Y r 2, Y r 3 a, Y r 4 a, Y r 13$ & $\begin{array}{l}\text { CI } 12633 / 5 * \text { Cappelle Desprez//Hybrid } 46 / \text { Cappelle Desprez/3/2 } \\
\text { *Professeur Marchal }\end{array}$ & United Kingdom \\
\hline Maris Widgeon & Yr3a, Yr4a, Yr16 & Holdfast/Cappelle Desprez & United Kingdom \\
\hline Mega & $\operatorname{Yr} 3 a, Y r 4 a, Y r 12$ & Cappelle/H 2596//6003 & United Kingdom \\
\hline Mercia & 1 & Talent/Virtue//Flanders & United Kingdom \\
\hline Moulin & Yr6, Yr14 & CB 306-Y-70/Maris Widgeon//Maris Hobbit & France \\
\hline Moro & Yr10, YrMor & PI $178383 / 2 *$ Omar & United States \\
\hline Mo(s) 490 & 1 & 1 & 1 \\
\hline Mo(w) 406 & I & I & l \\
\hline Mo(w) 470 & I & l & I \\
\hline Mo(w) 499 & I & I & 1 \\
\hline Norman & $\operatorname{Yr} 2, \operatorname{Yr} 6$ & TJB 268-175/(Sib) Hobbit & United Kingdom \\
\hline Pagode & / & (S)Composite Cross of 36 Cultivars & The Netherlands \\
\hline Paiimiot 113 wi & 1 & l & France \\
\hline PI 178383 & Yr10 + minor genes & 1 & Turkey \\
\hline Rendezvous & $\operatorname{Yr} 17$ & VPM 1/(Sib)Hobbit//Virtue & United Kingdom \\
\hline Resulka & YrRes & 1 & 1 \\
\hline Selkirk & Yr27 & Mcmurachy/Exchange//3*Redman & Canada \\
\hline Strampelli & Yr18 + APR QTL & Libero//San Pastore 14/Jacomtti 49 & Italy \\
\hline Strubes Dickkopf & $\operatorname{Yr} 25, \mathrm{YrSD}$ & I & Germany \\
\hline SXAF 4-7 & I & I & France \\
\hline Triticum spelta album & Yr5 & 1 & I \\
\hline Vilmorin 23 & $\operatorname{Yr} 4 a, \mathrm{YrV} 23$ & Melbor/Grosse Tete//Japhet/Parsel & France \\
\hline Vilmorin 27 & Yr3a, Yr4a, Yr16 & Dattel//Japhet/Parsel/3/Hatif Inversable/Bon Fermier & France \\
\hline VM 82-24-20-44 & 1 & VM 628-17-2/Rescler//VM 480-4-2-5 & France \\
\hline VPM 1 & $\operatorname{Yr} 17$ & Ae.Ve/Tr.Ca//3*Marne & France \\
\hline VPM $1 / 4 *$ Cook & $\operatorname{Yr} 17, \operatorname{Yr} 18+$ & / & Austria \\
\hline $83-508-42$ & / & l & France \\
\hline
\end{tabular}

${ }^{a}$ Pedigrees and origin of cultivars and lines are from http://genbank.vurv.cz/wheat/pedigree/pedigree.asp and http://www.ars-grin.gov; / = unknown.

${ }^{\mathrm{b}} \mathrm{DR}=$ durable resistance to yellow rust (YR). 
Yr9 and 'Suwon 11' $[\mathrm{YrSu}]$, first detected in 1994 and becoming predominant in 2000 to 2002), CYR33 (virulent on Suwon 11, first detected in 1997 and formally named in 2008), and Gui pathotype (the first race virulent on 'Guinong 22', 'Chuanmai 42', and other cultivars with $Y r 24, Y r 26$, and $Y r C H 42$, as well as $Y r 10$ in 2010). The main races identified from samples taken from the trial sites in different years are listed in Table 2.

Evaluation of YR response. YR responses at Tianshui (altitude $1,373 \mathrm{~m}$ asl, annual rainfall 450 to $560 \mathrm{~mm}$ ) were evaluated from 1993 to 2013. Cultivars and lines were grown in three-row $1.5-\mathrm{m}$ plots with a $0.2-\mathrm{m}$ row spacing. The highly susceptible (HS) cultivar 'Huixianhong' was sown perpendicular and adjacent to the test rows as a spreader to ensure ample inoculum and also to serve as a susceptible control. Artificial inoculations were performed with contemporary and prevalent pathotypes at the three-leaf stage in spring (Table 2). The scoring of YR response followed the standard 0-to-4 infection type (IT) scale described by McIntosh et al. (26). Maximum disease severities (MDS) - percentages of leaf area infected when disease severity on the control reached its maximum (90 to 100\%) around June 8 each year-were based on the modified Cobb scale (28). The data in 2000 and 2011 were not included in this article due to the poor disease development in the dry springs of these 2 years.

\section{Results}

Cultivars and lines with documented single major resistance gene or major gene combinations effective against $Y R$ at the adult-plant stage. The adult-plant reactions of 19 cultivars and lines with one or more major genes to YR during 1993 to 2013 are shown in Table 3 . Six cultivars were highly resistant (HR) or moderately resistant (MR), with IT 0 to 2, during 1993 to 2013, and the genes underlying the resistance in the cultivars were identified as Yr5, Yr10, Yr15, and other unknown genes. For example, PI 178383 (Yr10 + minor genes) (34), 'Rendezvous', and Triticum spelta album (Yr5) (23) displayed IT 0 in all 19 years. 'Gaby' (YrGaby) exhibited HR to MR with IT 0 to 2 in all 19 years, and 'Dippes Triumph' (2) and Hybrid 46 ( Yr3a, Yr4b, and H46) $(7,22)$ showed IT 0 in most years and IT 0; to 2 with lower MDS (less than 5\%) in a few years. 'Compair' ( $Y r 8$ and $\operatorname{Yr} 19)(9,29)$, 'Fenman' (Yrl and Yr2) (9,29), 'Heines Kolben' (Yr2 and $Y r 6)$ $(4,23)$, 'Norman' (Yr2 and Yr6) (30), 'Resulka' (YrRes) (11), and
'Strubes Dickkopf' (YrSD) (37) were HR or MR (IT 0; to 2) to MS (IT 3 to 4) with low MDS (less than 25\%) in all 19 years. Although the predominant races in the region changed from CYR29 to CYR33 and Gui pathotype during 1993 to 2013, these cultivars remained resistant. For example, $\operatorname{Yr} 8$ in Compair was overcome by race CYR29 in 1993, and resistance in Resulka and Strubes Dickkopf was compromised by CYR32 in 1999 to 2001, but the three cultivars had low MDS over a long period, indicating that unknown APR genes commonly provided effective YR resistance in various cultivars and lines.

The other seven cultivars displayed HR to MR, MS, or very susceptible (VS) responses during 1993 to 2013. For example, 'Heines VII' (Yr2, Yr25, and YrHVII) $(4,6,11)$ was susceptible to YR from 1993 to 2013, indicating that these genes were not effective against Chinese $P$. striiformis $\mathrm{f}$. tritici races and that there were no additional APR genes. 'Carstens V' (Yr32) (8,11), 'Selkirk' (Yr27) (27), 'Vilmorin 23' (Yr4a and YrV23) (7), and 'VPM 1' (Yr17) (3) were resistant, with IT 0; to 1, during 1993 to 1997 but became susceptible at different times after 1998. 'C591' (YrC591) (17) had IT 0 during 1993-1994, and IT 0;-1 in 1995-1996, 1996-1997, and 1997-1998 cropping seasons, but showed MR to YR, and MS responses after 1999, and, in 2005, it was HS, with a high MDS (60\%). The resistance became ineffective in these cultivars as new races emerged: CYR29 with virulence to Heines VII in the 1990s; YR31 with virulence to Carstens V in 1998; and CYR32 with virulence to C591, Selkirk, Vilmorin 23, and VPM 1 in 2001 (Tables 2 and 3). 'Moro' (Yrl0 and YrMor) $(10,24)$ had IT 0 to 0; from 1993 to 2010 and then became susceptible to YR (IT 2, 3, and 4) after 2012. This change was associated with the appearance of a new race overcoming resistance conferred by $\mathrm{Yr} 26 / \mathrm{YrCH} 42$, because it is now evident from worldwide data that virulence for these genes is associated with virulence to $\operatorname{YrlO}(20)$, even though YrlO is a clearly different gene located at a different locus on chromosome 1B.

Reaction of cultivars and lines with race nonspecific resistance to YR at the adult-plant stage. Based on classical resistance testing, the documented resistance genes in the cultivars and lines such as 'Cappelle Desprez' (Yr3a, Yr4a, and Yrl6) (35), 'Flanders' (Yrl, Yr3a, Yr4a, and Yr16) $(15,30)$, 'Hobbit' (Yr3, Yr4, Yr14, and YrHVII) (12), 'Ibis' (Yr1, Yr2, QYr.caas-2BS.1, and QYr.caas-6BS.1) (1), 'Joss Cambier' (Yr2 and Yr11) (22), 'Long-

Table 2. Predominant Puccinia striiformis f. sp. tritici races or pathotypes identified from naturally infected and inoculated nurseries in southeastern Gansu province during 1993 to 2013

\begin{tabular}{ll}
\hline Year & \multicolumn{1}{c}{ Races or pathotypes in decreasing order by frequency $^{\mathbf{a}}$} \\
\hline 1993 & CYR29, CYR30, CYR31, Lovrin13II, Lovrin13 VII, Su11, HY pathotypes \\
1994 & CYR29, CYR30, CYR31, Lovrin13 VII, Su11, HY, Su pathotypes \\
1995 & CYR31, CYR29, CYR30, Su11, HY, Lovrin pathotypes, Su pathotypes \\
1996 & CYR31, HY pathotypes, Su pathotypes, CYR29, CYR30 \\
1997 & CYR31, Su pathotypes, HY pathotypes \\
1998 & CYR31, Su7, Su10, Su14, CYR29 \\
1999 & Su7, Su14, Su10, CYR31, CYR29 \\
2001 & CYR32, Su14, Su3, Su7, Su4, Su10, Su11, CYR29 \\
2002 & Su14, CYR32, Su4, Su7, Su5, CYR31 \\
2003 & Su14, CYR32, Su4, Su7, Su5, CYR31 \\
2004 & Su14, CYR32, Su7, Su4, Su 5, CYR31 \\
2005 & CYR33, CYR32, Su7, Su4, CYR31 \\
2006 & CYR33, CYR32, Su4, Su13, Su7, Su5, CYR31 \\
2007 & CYR33, CYR32, Su7, Su4, Su13, Su5, CYR31 \\
2008 & CYR33, CYR32, Su7, Su4, HY8, CYR31 \\
2009 & CYR33, CYR32, Su7, Su4, HY8, CYR29 \\
2010 & CYR33, CYR32, Su7, Su4, HY8, CYR29 \\
2012 & CYR33, CYR32, Su4, Su7, Gui2-9, Gui2-14 \\
2013 & CYR33, CYR32, Su4, Su7, Gui2-9, Gui2-14 \\
\hline
\end{tabular}

${ }^{\text {a }}$ Data provided by Q. Z. Jia and S. Q. Cao, Institute of Plant Protection, Gansu Academy of Agricultural Science, Lanzhou. Races and pathotypes were identified by a set of wheat differentials for P. striiformis f. sp. tritici in China using 17 wheat genotypes (Trigo Eureka, Fulhard, Letescens 128 , Mentana, Virgilio, Abbondanza, Early Premium, Funo, Danish 1, Jubilejina 2, Fengchan 3, Lovrin 13, Kangyin 655, Suwon 11, Zhong 4, Lovrin 10, and Hybrid 46), and supplemental differential wheat lines Guinong 22 and so on. Lovrin 13, Su, HY, and Gui indicate that the pathotypes were virulent on cultivars Lovrin 13, Suwon, Hybrid 46, and Guinong 22, respectively. Lovrin 13 II and Lovrin 13 VII = pathotypes of Lovrin 13 type 2 and Lovrin 13 type 7, respectively; HY8 is the Hybrid 46 type 8; Su3, SY4, Su5, Su7, Su10, Su11, Su13, and Su14 are the pathotypes of Suwon type 3, Suwon type 4, Suwon type 5, Suwon type 7, Suwon type 10, Suwon type 11, Suwon type 13, and Suwon type 14, respectively. 
bow' (Yr1, Yr2, Yr6, Yr9, and Yr13), 'Maris Huntsman' (Yr2, Yr3a, $Y r 4 a$, and $Y r 13)$, 'Maris Widgeon' (Yr3a, Yr4a, and Yr16), 'Mega' (Yr3a, Yr4a, and Yr12), 'Moulin' (Yr6 and Yr14), and 'Vilmorin 27' (Yr3a, Yr4a, and Yrl6) showed race nonspecific resistance, which is often referred to as APR or slow-rusting resistance (6). In the field trials (Table 4), four cultivars-Ibis, Mega, 'Strampelli' (21), and 'VPM 1/4*Cook' (probably at least $Y r 17$ and $Y r 18$ ) - had IT 0 in most years, and 0; to 2 in a few years; and Flanders, Hobbit, Joss Cambier, 'Libellula' (21), Longbow, Maris Huntsman, Maris Widgeon, and Vilmorin 27 exhibited MR to MS with lower MDS (less than 25\%) during 1993 to 2013. However, the MDS in Cappelle Desprez increased gradually during 1993 to 2013. In fact, it was not known whether these genes or other genes for seedling (all-stage) resistance and APR contributed to the observed responses at Tianshui in the period.
The other cultivars and lines with unknown resistance genes, such as 'Atou', had IT 0 to 2 in most years and IT 3 to 4 in only 1998, 2001, 2005, and 2013. The susceptible response in Atou could be caused by different races becoming predominant in the period; for example, the Su7 pathotype, CYR32, CYR33, and Gui pathotype become the predominant race in 1999, 2001, 2005, and 2013, respectively. 'Elite Le Peuple', 'Flinor', and Moulin had IT of 0; to 2 in most years. 'Champlein' and 'Little Joss' were MR to MS with IT 0 to 3. 'Bouquet' and 'Pagode' were MR to MS from 1993 to 2013 and, particularly, 'Holdfast' had IT 4 and MDS of $45 \%$ in 2005 but was heavily rusted in later years, perhaps caused by the epidemic of CYR33 in the region in 2005.

Adult-plant reactions of cultivars and lines with unknown resistance genes. Reactions of 17 cultivars with unknown resistance genes to YR are shown in Table 5. Four cultivars-'FR81-1',

Table 3. Adult-plant reactions of 19 wheat cultivars with major genes to mixed prevalent races of Chinese Puccinia striiformis f. sp. tritici in the field during 1993 to 2013

\begin{tabular}{|c|c|c|c|c|c|c|c|c|c|c|c|c|c|c|c|c|c|c|c|c|}
\hline \multirow[b]{2}{*}{ Cultivar, line } & \multicolumn{19}{|c|}{ Infection type (0-4) } & \multirow[b]{2}{*}{ MDS $^{\mathbf{a}}$} \\
\hline & 1993 & 1994 & 1995 & 1996 & 1997 & 1998 & 1999 & 2001 & 2002 & 2003 & 2004 & 2005 & 2006 & 2007 & 2008 & 2009 & 2010 & 2012 & 2013 & \\
\hline Carstens V & $0 ;-2$ & $1-2$ & $0 ;-2$ & $0 ;-1$ & $0 ;-2$ & $2-3$ & $2-3$ & 0 & $3-4$ & 0 & $2-4$ & $3-4$ & 3 & $3-4$ & $3-4$ & $3-4$ & $3-4$ & $3-4$ & $3-4$ & $0-50$ \\
\hline Compair & $2-3$ & $2-3$ & $2-3$ & $2-4$ & $3-4$ & $3-4$ & $2-3$ & $3-4$ & $1-2$ & 0 & 0 & $1-4$ & $1-2$ & 3 & 0 & $2-3$ & $2-3$ & 0 & 0 & $0-25$ \\
\hline C591 & 0 & 0 & 0 & 1 & 1 & 1 & $2-3$ & $3-4$ & $3-4$ & $1-2$ & $0 ;-1$ & $2-4$ & 0 & 0 & 0 & $2-3$ & $2-3$ & 0 & $0 ;-1$ & $0-60$ \\
\hline Dippes Triumph & 0 & 0 & 0 & 0 & 1 & 0 & 0 & 0 & $1-2$ & 0 & 0 & 0 & 0 & $0 ;-1$ & 0 & 0 & 0 & 0 & 0 & $0-5$ \\
\hline Fenman & 0 & 0 & 0 & 0 & 0 & 0 & 0 & 0 & 0 & 0 & 0 & $3-4$ & 0 & 0 & 0 & $0 ;-1$ & 0 & 0 & 0 & $0-25$ \\
\hline Gaby & $0 ;-1$ & 0 & 0 & 0 & $0 ;-2$ & 1 & 0 & $0 ;-1$ & 0 & $0 ;-1$ & $0 ;-2$ & $0 ;-2$ & 0 & $0 ;-1$ & 0 & $0 ;-2$ & $0 ;-1$ & $0 ;-2$ & $0 ;-2$ & $0-40$ \\
\hline Heines VII & $0 ;-3$ & $0 ;-3$ & $0 ;-3$ & $0 ;-3$ & $0 ;-3$ & $2-3$ & $3-4$ & 3 & 3 & $1-3$ & $3-4$ & 3 & $2-3$ & $2-3$ & 3 & $3-4$ & $2-3$ & $2-3$ & $3-4$ & $5-60$ \\
\hline Heines Kolben & 0 & 0 & 0 & $2-3$ & 0 & 0 & 0 & 0 & 0 & 0 & $0 ;-1$ & 0 & 0 & 0 & 0 & 3 & 2 & 0 & 0 & $0-5$ \\
\hline Hybrid 46 & 0 & 0 & 0 & 0 & 0 & 0 & 0 & 0 & 0 & 0 & 0 & 0 & 0 & 0 & 0 & 0 & 0 & 0 & 0 & $0-1$ \\
\hline Moro & 0 & 0 & 0 & 0 & 0 & 1 & 0 & 0 & 0 & 0 & 0 & 0 & 0 & 0 & 0 & 0 & 0 & $2-3$ & $2-4$ & $0-15$ \\
\hline Norman & 1 & $1-2$ & $0 ;-2$ & $1-2$ & $0 ;-1$ & 0 & $2-3$ & 1 & 1 & 0 & $0 ;-2$ & $0 ;-2$ & 0 & 0 & $0 ;-2$ & $1-2$ & 1 & 1 & 0 & $0-5$ \\
\hline PI 178383 & 0 & 0 & 0 & 0 & 0 & 0 & 0 & 0 & 0 & 0 & 0 & 0 & 0 & 0 & 0 & 0 & 0 & 0 & 0 & 0 \\
\hline Rendezvous & 0 & 0 & 0 & 0 & 0 & 0 & 0 & 0 & 0 & 0 & 0 & 0 & 0 & 0 & 0 & 0 & 0 & 0 & 0 & 0 \\
\hline Resulka & $0 ;-1$ & $1-2$ & $0 ;-1$ & $1-2$ & $0 ;-1$ & $2-3$ & $1-2$ & $3-4$ & $2-3$ & $2-3$ & $2-3$ & 3 & $2-3$ & $2-3$ & $2-3$ & 3 & 3 & $2-3$ & $2-3$ & $1-15$ \\
\hline Selkirk & $0 ;-1$ & 1 & 0 & $0 ;-1$ & 0 & 1 & $3-4$ & $3-4$ & $3-4$ & $3-4$ & $3-4$ & 4 & $2-3$ & 4 & 4 & $3-4$ & 3 & $1-4$ & $2-4$ & $1-60$ \\
\hline Strubes Dickkopf & $0 ;-1$ & $0 ;-1$ & $0 ;-2$ & $0 ;-2$ & 0 & 0 & $2-3$ & $3-4$ & $2-3$ & 0 & 0 & $3-4$ & 0 & 0 & 3 & $2-3$ & $2-3$ & 3 & 3 & $0-25$ \\
\hline Triticum spelta album & 0 & 0 & 0 & 0 & 0 & 0 & 0 & 0 & 0 & 0 & 0 & 0 & 0 & 0 & 0 & 0 & 0 & 0 & 0 & 0 \\
\hline Vilmorin 23 & $0 ;-1$ & $0 ;-2$ & $0 ;-2$ & $0 ;-2$ & $1-2$ & $1-2$ & $1-2$ & $3-4$ & $3-4$ & 0 & $0 ;-1$ & $3-4$ & $0 ;-2$ & $0 ;-1$ & $0 ;-2$ & $3-4$ & $2-3$ & $2-4$ & $2-4$ & $0-60$ \\
\hline VPM 1 & $0 ;-1$ & $0 ;-2$ & 0 & $0 ;-2$ & 0 & 0 & $0 ;-2$ & $3-4$ & $3-4$ & 0 & $1-2$ & $3-4$ & $1-2$ & $0 ;-2$ & 3 & $1-2$ & $1-2$ & 0 & 4 & $0-25$ \\
\hline Huixianhong $(\mathrm{CK})^{\mathrm{b}}$ & 4 & 4 & 4 & 4 & 4 & 4 & 4 & 4 & 4 & 4 & 4 & 4 & 4 & 4 & 4 & 4 & 4 & 4 & 4 & $90-100$ \\
\hline
\end{tabular}

${ }^{\mathrm{a}} \mathrm{MDS}=$ maximum disease severity $(\%)$; the data range across 19 years.

${ }^{\mathrm{b}}$ Huixianhong, a winter wheat landrace from Henan province of China, is highly susceptible to most Chinese races of Puccinia striiformis f. sp. tritici in both the seedling and adult-plant stages, as a susceptible check in the field.

Table 4. Adult-plant reactions of wheat cultivars with race nonspecific resistance to mixed prevalent races of Chinese Puccinia striiformis f. sp. tritici in the field during 1993 to 2013

\begin{tabular}{|c|c|c|c|c|c|c|c|c|c|c|c|c|c|c|c|c|c|c|c|c|}
\hline \multirow[b]{2}{*}{ Cultivar, line } & \multicolumn{19}{|c|}{ Infection type $(0-4)$} & \multirow[b]{2}{*}{ MDS $^{\mathbf{a}}$} \\
\hline & 1993 & 1994 & 1995 & 1996 & 1997 & 1998 & 1999 & 2001 & 2002 & 2003 & 2004 & 2005 & 2006 & 2007 & 2008 & 2009 & 2010 & 2012 & 2013 & \\
\hline Atou & $1-2$ & 2 & $1-2$ & $1-2$ & $0 ;-1$ & $2-3$ & $1-2$ & $3-4$ & $1-2$ & $1-2$ & 2 & $1-4$ & 2 & $1-2$ & $1-2$ & 2 & $1-2$ & 2 & $2-3$ & $5-10$ \\
\hline Bouquet & $1-2$ & 2 & $1-2$ & 2 & 0 & $2-3$ & $1-2$ & $3-4$ & $3-4$ & $2-3$ & $2-3$ & $1-3$ & $2-3$ & $2-3$ & $2-3$ & $3-4$ & $2-3$ & $2-3$ & 0 & $5-15$ \\
\hline Cappelle Desprez & $0 ;-2$ & $1-2$ & $0 ;-2$ & $0 ;-2$ & $0 ;-2$ & 0 & $1-3$ & $3-4$ & $2-3$ & 0 & $2-4$ & $2-4$ & 1 & $0 ;-2$ & 0 & $2-4$ & $3-4$ & $2-3$ & 3 & $0-30$ \\
\hline Champlein & $0 ;-1$ & 1 & 1 & 1 & 0 & 1 & 0 & $2-3$ & $2-3$ & $1-2$ & $1-2$ & 3 & $2-3$ & $1-2$ & $1-2$ & $2-3$ & $1-2$ & $1-2$ & 0 & $0-15$ \\
\hline Elite Le Peuple & 0 & 0 & 0 & 0 & 0 & 0 & 0 & 0 & 0 & 0 & 0 & $0 ;-1$ & 0 & $0 ;-1$ & $0 ;-1$ & 0 & 0 & 0 & $0 ;-1$ & $0-15$ \\
\hline Flanders & 0 & 0 & 0 & 0 & 0 & 0 & 0 & 3 & 0 & 0 & 0 & 0 & 0 & 0 & 0 & 0 & 0 & 0 & 0 & $0-5$ \\
\hline Flinor & $0 ;-1$ & $0 ;-1$ & $0 ;-1$ & $0 ;-1$ & $0 ;-1$ & $0 ;-1$ & 0 & 3 & 0 & 0 & $0 ;-1$ & 0 & 0 & 0 & 0 & $0 ;-1$ & 0 & 0 & 0 & $0-5$ \\
\hline Hobbit & $0 ;-2$ & $0 ;-2$ & $0 ;-3$ & 2 & $0 ;-2$ & $0 ;-1$ & $1-2$ & $3-4$ & $2-3$ & $1-2$ & $2-4$ & $2-4$ & $1-2$ & $0 ;-2$ & $0 ;-1$ & $1-3$ & $1-2$ & $2-4$ & $2-4$ & $5-15$ \\
\hline Holdfast & $0 ;-1$ & 0 & 0 & 0 & 0 & 0 & $3-4$ & $3-4$ & $3-4$ & $0 ;-1$ & $0 ;-1$ & $3-4$ & 0 & $0 ;-1$ & 4 & $3-4$ & $3-4$ & $2-3$ & $2-3$ & $0-45$ \\
\hline Ibis & 0 & 0 & 0 & 0 & 0 & 0 & 0 & 0 & 0 & $0 ;-1$ & 0 & 0 & 0 & 0 & 0 & 0 & 0 & 0 & 0 & $0-1$ \\
\hline Joss Cambier & $0 ;-2$ & $0 ;-2$ & $0 ;-2$ & 0 & $0 ;-2$ & 1 & $2-3$ & $3-4$ & $3-4$ & 0 & $1-3$ & $0 ;-3$ & $1-2$ & $0 ;-2$ & 2 & $2-3$ & 2 & $2-3$ & $0 ;-3$ & $0-25$ \\
\hline Libellula & 0 & 2 & $2-3$ & $2-3$ & 2 & $2-3$ & $2-3$ & $2-3$ & $2-3$ & $0 ;-2$ & $1-2$ & $3-4$ & $2-3$ & $3-4$ & $2-3$ & $3-4$ & $2-3$ & $0 ;-2$ & $3-4$ & $5-10$ \\
\hline Little Joss & $1-2$ & $1-2$ & 1 & 1 & $0 ;-2$ & 0 & $0 ;-1$ & 3 & $2-3$ & 0 & 0 & $0 ;-2$ & 0 & $0 ;-1$ & 0 & $0 ;-1$ & 0 & 0 & 0 & $0-5$ \\
\hline Longbow & $0 ;-1$ & 0 & 0 & 0 & 0 & 0 & 0 & $2-3$ & 0 & 0 & $0 ;-1$ & $0 ;-2$ & 0 & 0 & $0 ;-1$ & $2-4$ & 0 & $0 ;-2$ & 0 & $0-5$ \\
\hline Maris Huntsman & $1-2$ & $0 ;-1$ & $0 ;-2$ & $1-2$ & $1-2$ & 1 & 0 & 3 & $2-3$ & 0 & $0 ;-2$ & $1-4$ & 0 & 3 & 3 & $2-3$ & 3 & $3-4$ & 4 & $0-15$ \\
\hline Maris Widgeon & $1-2$ & $1-2$ & $1-2$ & $0 ;-1$ & 0 & 0 & $1-2$ & $3-4$ & $3-4$ & 0 & $3-4$ & $1-3$ & 0 & $0 ;-1$ & $3-4$ & $1-3$ & $3-4$ & $0 ;-2$ & 0 & $0-15$ \\
\hline Mega & 0 & $0 ;-1$ & 0 & 0 & $0 ;-1$ & 0 & 0 & 0 & 0 & 0 & 0 & $0 ;-1$ & 0 & $0 ;-1$ & 0 & 0 & 0 & 0 & 0 & $0-10$ \\
\hline Moulin & $0 ;-1$ & $0 ;-1$ & 1 & $0 ;-1$ & $0 ;-1$ & 0 & 0 & 3 & 1 & 0 & 0 & $0 ;-1$ & 0 & 0 & 0 & $1-2$ & 0 & $0 ;-1$ & 0 & $0-5$ \\
\hline Pagode & $0 ;-1$ & 0 & 0 & 0 & 0 & 0 & 0 & $3-4$ & $2-3$ & 0 & $0 ;-1$ & $0 ;-1$ & 0 & 0 & $0 ;-1$ & $2-3$ & $2-3$ & $1-2$ & 2 & $0-8$ \\
\hline Strampelli & $0 ;-1$ & $0 ;-2$ & 0 & $0 ;-3$ & $0 ;-3$ & 0 & $1-2$ & 0 & 0 & 0 & $1-2$ & $0 ;-1$ & $0 ;-1$ & $1-2$ & $0 ;-1$ & $0 ;-1$ & $0 ;-1$ & $0 ;-1$ & $0 ;-1$ & $0-8$ \\
\hline Vilmorin 27 & $0 ;-2$ & $0 ;-2$ & 0 & 0 & $0 ;-2$ & 0 & 0 & $3-4$ & $2-3$ & 0 & 1 & $1-3$ & 1 & 0 & $0 ;-1$ & $0 ;-1$ & 1 & 0 & 0 & $0-8$ \\
\hline VPM 1/4*Cook & 0 & 0 & 0 & 0 & 0 & 0 & 0 & 0 & 0 & 0 & 0 & $0 ;-2$ & 0 & $1-2$ & 0 & 0 & 0 & $1-2$ & $0 ;-2$ & $0-15$ \\
\hline Huixianhong $(\mathrm{CK})^{\mathrm{b}}$ & 4 & 4 & 4 & 4 & 4 & 4 & 4 & 4 & 4 & 4 & 4 & 4 & 4 & 4 & 4 & 4 & 4 & 4 & 4 & $90-100$ \\
\hline
\end{tabular}

a MDS = maximum disease severity $(\%)$; the data range across 19 years.

${ }^{\mathrm{b}}$ Huixianhong, a winter wheat landrace from Henan province of China, is highly susceptible to most Chinese races of Puccinia striiformis f. sp. tritici in both the seedling and adult-plant stages, as a susceptible check in the field. 
'Mo(w) 499', 'Mo(w) 406', and 'German 8661'-had IT 0 from 1993 to 2013. 'Lperfer' was very resistant, with IT 0 to 0 ; in most years. 'Paiimiot113wi', '83-508-42', 'Aquila I', 'Cik Vee', and 'Mo(w) 470' showed HR to MR, with IT 0 to 2. Other cultivars, such as 'Jubilar' and 'SXAF4-7', exhibited MR to MS with low MDS (less than 20\%) in most years.

Use of European cultivars and lines in wheat breeding. Ten commercial winter wheat cultivars were released in this region for highland terrace or lowland valley cultivation during 2004 to 2013 (Table 6). These included 'Lantian 15', 'Lantian 18', 'Lantian 19', 'Lantian 20', 'Lantian 22', 'Lantian 23', 'Lantian 25', 'Lantian 26', 'Lantian 27', and 'Lantian 31'. The YR resistances in these cultivars were derived from Ibis, Flinor, Mega, Cappelle Desprez, 'German 2', SXAF4-7, 'Mo(s) 311', Flanders, Norman, and Longbow, respectively, and they have shown effective YR resistance since they were released for commercial production from 2004 to 2013. Lantian 15, Lantian 22, Lantian 23, Lantian 25, Lantian 26, and Lantian 31 have been grown in southeastern Gansu for many years and still exhibited highly effective APR to YR, indicating that the use of APR could be a promising strategy for sustainable control of YR in this area. Lantian 18, Lantian 19, Lantian 20, and Lantian 27 showed moderate to high resistance to YR at the seedling stage, and high resistance at the adult-plant stage, indicating that they had all-stage resistance for YR. Lantian 18 and Lantian 20 have also shown potentially durable resistance to powdery mildew (data not shown), indicating that they may possess APR genes besides the major genes to YR.

\section{Discussion}

Climatic conditions, geographic characteristics, and cropping systems in southeastern Gansu are ideal for year-round cycling of P. striiformis f. tritici $(19,32)$. Continuing epidemics with high levels of inoculum are associated with the generation and maintenance of high levels of pathogenic variability in the pathogen population, which possibly also includes sexual reproduction on barberry (38). Over the last three decades (from 1990 to 2013), severe YR epidemics occurred in 3 years and moderate epidemics occurred in 16 years, and the predominant $P$. striiformis $\mathrm{f}$. tritici races sampled from wheat in this region have been changed from CYR29 to CYR33 and Gui (Table 2). The change in the pathogen population resulted in ineffectiveness of resistance in many cultivars for 3 to 5 years after release (13). Presence of CYR29 resulted in the ineffectiveness of resistance in 'Lovrin 10', 'Lovrin 13', and other cultivars with $\operatorname{Yr} 9$ (1B.1R translocation); CYR31 was virulent on Hybrid 46, with CYR32 combining virulences on Hybrid 46 and Fan 6 and its derivatives and virulent to $Y r 1, Y r 2, Y r 3, Y r 4, Y r 6, Y r 7, Y r 9, Y r 17, Y r 22, Y r 23$, $Y r 27, Y r A, Y r C V 1, Y r C V 2, Y r C V 3, Y r G, Y r S D$, and $Y r S O$ (33); CYR33 was virulent on Suwon 11; and the Gui pathotype was virulent on Chuanmai 42, Moro (Yr10), Guinong 22, Lantian 17 (probably Yr26), and Lantian 30 (probably Yr26) during 1993 to 2013. Based on our field evaluation, C591, Carstens V, Resulka, Selkirk, Strubes Dickkopf, Vilmorin 23, VPM 1, Bouquet, Cappelle Desprez, Champlein, Holdfast, Maris Huntsman, Maris

Table 5. Adult-plant reactions of wheat cultivars with unknown resistance genes to mixed prevalent races of Chinese Puccinia striiformis f. sp. tritici in the field during 1993 to 2013

\begin{tabular}{|c|c|c|c|c|c|c|c|c|c|c|c|c|c|c|c|c|c|c|c|c|}
\hline \multirow[b]{2}{*}{ Cultivar, line } & \multicolumn{19}{|c|}{ Infection type (0-4) } & \multirow[b]{2}{*}{ MDS $^{\mathbf{a}}$} \\
\hline & 1993 & 1994 & 1995 & 1996 & 1997 & 1998 & 1999 & 2001 & 2002 & 2003 & 2004 & 2005 & 2006 & 2007 & 2008 & 2009 & 2010 & 2012 & 2013 & \\
\hline $83-508-42$ & 0 & 0 & 0 & 0 & 0 & 0 & $1-2$ & $1-2$ & 0 & 0 & 0 & 0 & 0 & 0 & 0 & 0 & 0 & 0 & 0 & $0-5$ \\
\hline Aquila I & $0 ;-1$ & $0 ;-1$ & 1 & 0 & $0 ;-1$ & 0 & $0 ;-2$ & $1-2$ & $1-2$ & 0 & 0 & 0 & 0 & 0 & 0 & 0 & 0 & 0 & 0 & $0-5$ \\
\hline Cik Vee & 0 & 0 & 0 & 1 & 0 & 0 & 0 & $1-2$ & 0 & $0 ;-1$ & 1 & 1 & $0 ;-1$ & $0 ;-1$ & $0 ;-1$ & $1-2$ & 1 & $0 ;-1$ & $0 ;-1$ & $0-5$ \\
\hline FR 81-1 & 0 & 0 & 0 & 0 & 0 & 0 & 0 & 0 & 0 & 0 & 0 & 0 & 0 & 0 & 0 & 0 & 0 & 0 & 0 & 0 \\
\hline German 2 & 0 & 0 & 0 & 0 & 0 & 0 & 0 & 0 & $1-2$ & 0 & 0 & 0 & 0 & 0 & 0 & 0 & 0 & 0 & 0 & $0-5$ \\
\hline German 8661 & 0 & 0 & 0 & 0 & 0 & 0 & 0 & 0 & 0 & 0 & 0 & 0 & 0 & 0 & 0 & 0 & 0 & 0 & 0 & 0 \\
\hline Jubilar & $0 ;-1$ & $0 ;-1$ & $0 ;-1$ & $0 ;-1$ & $0 ;-2$ & $0 ;-1$ & 1 & $3-4$ & $0 ;-2$ & $1-2$ & $1-2$ & $1-4$ & 2 & $1-2$ & $1-2$ & $2-3$ & $1-2$ & $1-4$ & 2 & $5-12$ \\
\hline Lperfer & 0 & 0 & 0 & 0 & 0 & 0 & 0 & 0 & 0 & 0 & 0 & 0 & 0 & 0 & 0 & 0 & 0 & 0 & 0 & $0-5$ \\
\hline Mercia & 0 & 0 & 0 & 0 & 0 & 0 & 0 & 2 & 0 & 0 & 0 & 0 & 0 & 0 & 0 & 0 & 0 & 0 & 0 & $0-5$ \\
\hline Mo(s) 490 & 0 & 0 & 0 & 0 & 0 & 0 & 0 & $1-2$ & 1 & $0 ;-1$ & 1 & $0 ;-1$ & 1 & 1 & 1 & $1-2$ & 1 & $0 ;-1$ & $1-2$ & $0-5$ \\
\hline $\operatorname{Mo}(w) 406$ & 0 & 0 & 0 & 0 & 0 & 0 & 0 & 0 & 0 & 0 & 0 & 0 & 0 & 0 & 0 & 0 & 0 & 0 & 0 & 0 \\
\hline Mo(w) 470 & $0 ;-1$ & $0 ;-1$ & $0 ;-1$ & $0 ;-1$ & $0 ;-1$ & 0 & $1-2$ & 0 & 0 & $0 ;-1$ & $0 ;-2$ & $0 ;-1$ & $0 ;-1$ & $0 ;-1$ & $0 ;-1$ & $1-2$ & $0 ;-2$ & $0 ;-1$ & $1-2$ & $0-5$ \\
\hline Mo(w) 499 & 0 & 0 & 0 & 0 & 0 & 0 & 0 & 0 & 0 & 0 & 0 & 0 & 0 & 0 & 0 & 0 & 0 & 0 & 0 & 0 \\
\hline Paiimiot113wi & 1 & 1 & 1 & 1 & 1 & 1 & $1-2$ & $1-2$ & 2 & 2 & 1 & $1-2$ & 2 & $1-2$ & $1-2$ & 2 & 2 & 1 & $1-2$ & $1-5$ \\
\hline SXAF4-7 & $0 ;-1$ & $0 ;-1$ & $0 ;-1$ & $0 ;-1$ & $0 ;-1$ & 4 & $2-3$ & $2-3$ & 0 & $1-3$ & $1-2$ & $1-2$ & $1-2$ & $1-2$ & $1-2$ & $2-3$ & $2-3$ & $1-2$ & $2-3$ & $0-8$ \\
\hline VM 82-24-20-44 & 0 & 0 & 0 & 0 & 0 & 0 & 0 & 0 & 0 & 0 & 0 & 0 & 0 & 0 & 0 & 0 & 0 & 0 & 0 & $0-5$ \\
\hline Huixianhong $(\mathrm{CK})^{\mathrm{b}}$ & 4 & 4 & 4 & 4 & 4 & 4 & 4 & 4 & 4 & 4 & 4 & 4 & 4 & 4 & 4 & 4 & 4 & 4 & 4 & $90-100$ \\
\hline
\end{tabular}

${ }^{a}$ MDS = maximum disease severity $(\%)$; the data range across 19 years.

${ }^{\mathrm{b}}$ Huixianhong, a winter wheat landrace from Henan province of China, is highly susceptible to most Chinese races of Puccinia striiformis f. sp. tritici in both the seedling and adult-plant stages, as a susceptible check in the field.

Table 6. Commercial winter wheat cultivars with yellow rust (YR) resistance genes derived from European cultivars and lines

\begin{tabular}{|c|c|c|c|c|c|}
\hline \multirow[b]{2}{*}{ Commercial cultivar } & \multirow[b]{2}{*}{ Pedigree $^{b}$} & \multicolumn{2}{|c|}{ Resistance to $\mathbf{Y} \mathbf{R}^{\mathbf{a}}$} & \multirow[b]{2}{*}{ Growing region } & \multirow[b]{2}{*}{ Year released } \\
\hline & & Seedling & Adult & & \\
\hline Lantian 15 & Ibis/Lantian $10^{\mathrm{s}}$ & MS & HR & Highland terrace & 2004 \\
\hline Lantian 18 & Flinor/Lovrin $13^{\mathrm{s}}$ & HR & HR & Highland terrace & 2007 \\
\hline Lantian 19 & Mega/Lantian $10^{\mathrm{s}}$ & HR & HR & Highland terrace & 2007 \\
\hline Lantian 20 & Cappelle Desprez/Lantian $10^{\mathrm{s}}$ & HR & HR & Highland terrace & 2007 \\
\hline Lantian 22 & German $2 /$ Lantian $11^{\mathrm{s}}$ & MS & HR & Highland terrace & 2007 \\
\hline Lantian 23 & SXAF 4-7/87-121 & MS & HR & Lowland valley & 2007 \\
\hline Lantian 25 & 92-72-3-3'Mo(s) 311 & MS & HR & Lowland valley & 2009 \\
\hline Lantian 26 & Lantian $10^{s^{\prime}}$ Flanders & MS & HR & Highland terrace & 2010 \\
\hline Lantian 27 & Norman/Lantian $10^{\mathrm{s}}$ & HR & HR & Highland terrace & 2010 \\
\hline Lantian 31 & Longbow/Lantian $10^{\mathrm{s}}$ & MS & HR & Highland terrace & 2013 \\
\hline
\end{tabular}

a The test of seedling-stage resistance to YR in each cultivar was inoculated by races of CYR29, CYR31, CYR32, CYR33, Lovrin 13 III, and Su pathotypes, respectively. $\mathrm{MS}=$ moderately susceptible and $\mathrm{HR}=$ highly resistant. The test of adult-plant stage resistance to YR in these cultivars was inoculated by mixed races same as its seedling-stage plant.

b Superscript "s" indicates susceptible to YR. 
Widgeon, Jubilar, and SXAF4-7 were susceptible to YR during the epidemics caused by CYR32.

In southeastern Gansu, many cultivars with seedling resistance or single major genes became susceptible to YR within 3 to 5 years after release into commercial production. From the 1950s to 1960s, many foreign cultivars with YR resistance were released directly into production in southeastern Gansu. For example, Lovrin 10, Lovrin 13, 'Abbondanza', 'Funo', and 'Jubilejna II grew in the region but many of them had a short life in commercial production. From the 1970s to 1980s, many foreign cultivars and lines with YR resistance were used in wheat breeding program. 'Tianxuan 15' and 'Tianxuan 16', with YR resistance derived from Abbondanza; 'Zhongliang 1', 'Zhongliang 2', and 'Zhongliang 3', with YR resistance from Funo; and 'Zhongliang 13', 'Zhongliang 14', and Lantian 1, with YR resistance from Lovrin 13 also had short lives in production because they have only seedling resistance genes. However, two Italian cultivars, Strampelli and Libellula, with APR genes have remained resistant to YR in this region over the past four decades. In the period since 1993, deployment of different resistance genes in the highland terrace regions (oversummering area for $P$. striiformis f. tritici) and lowland valleys (overwintering area) (36) and using a diversity of resistance, including seedling resistance, APR was employed in wheat breeding programs, which could be a sustainable way to control YR in this area (39). Many foreign cultivars and lines with different YR resistance genes were evaluated in field trials and some were used in wheat breeding programs. A series of commercial cultivars were developed by use of different effective resistance sources such as $\mathrm{Yrl} 2$ and $\mathrm{Yrl6}$, as well as some unknown genes, and these commercial cultivars were grown in the oversummering or overwintering regions (Table 6). Lantian 15, Lantian 18, Lantian 19 (possibly Yrl2), Lantian 20 (possibly Yr16), 'Lantian 21', Lantian 22, Lantian 26, Lantian 27, Lantian 31, Strampelli $(Y r 18+)$, and Libellula $(Y r 18+)$ were grown in the oversummering region, whereas Lantian 23, 'Lantian 24' (probably Yr26 +), and Lantian 25 were grown in overwintering regions. These cultivars are still resistant and provide effective control of YR in this region. Many major genes were overcome by predominant races in different periods, and only $\mathrm{Yr} 5$ and $\mathrm{Yr} 15$ are still effective against YR in southeastern Gansu. However, APR to $\mathrm{YR}$ in wheat, which is generally race nonspecific and quantitatively inherited, is providing durable protection against the disease (6). Pyramiding four to five minor resistance genes can achieve near-immune resistance and long-lasting protection from the rusts (31). Therefore, the use of APR or slow-rusting genes in wheat breeding programs is a promising strategy for sustainable control of YR in southeastern Gansu. For example, European Ibis, Flinor, Mega, Cappelle Desprez, Flanders, Longbow, and Holdfast, with documented APR for YR, have been successfully used in wheat breeding program, and commercial Lantian 15, Lantian 18, Lantian 19, Lantian 20, Lantian 26, Lantian 31, and Zhongliang 30, with YR resistance derived from these cultivars, still showed high APR for YR in the field.

Based on the YR responses of 57 cultivars in Tianshui during 1993 to 2013 (Tables 3, 4, 5, and Supplementary Table 1), Dippes Triumph, Flanders, Flinor, FR 81-1, German 2, German 8661, Hybrid 46 (Yr4 +), Ibis, Mega, Mo(w) 499, Mo(w) 406, PI 178383 $($ YrlO +), Rendezvous $(Y r 17+)$, T. spelta album (Yr5), and VPM $1 / 4 *$ Cook $($ Yrl + ) were highly resistant (IT 0 to 0 ;) to YR in all 19 years. They carried major genes (seedling and APR) and undoubtedly other unknown genes that can be utilized in future breeding. Cappelle Desprez, Compair, Heines Kolben, Hobbit, Joss Cambier, and Maris Huntsman exhibited MR to MS with low MDS (less than 30\%) in all 19 years; these materials can be used in future wheat breeding programs for gene deployment and gene pyramiding. Gaby, with the single major gene $Y r G a b y$, was HR to MR with lower MDS (0 to 40\%); pyramiding YrGaby and other genes in an elite genotype could be an effective way for improving resistance in wheat breeding. In contrast, C591 (YrC591), Carstens V $(Y r C V)$, Heines VII $(Y r 2, Y r 25, Y r H 2 V I I)$, Moro (Yr10), Strubes Dickkopf $(Y r S D)$, Vilmorin 23 (Yr4a, Yr23), and VPM 1 (Yr17) became susceptible to $\mathrm{YR}$ in recent years, indicating that $\mathrm{Yr}$, $Y r 4 a, Y r 10, Y r 17, Y r 23, Y r 25, Y r S D$, and $Y r C 591$ were not effective against current Chinese $P$. striiformis f. tritici races.

In this study, the cultivars and lines shown in Table 4 were identified as having race-nonspecific resistance to $\mathrm{YR}$, based on the YR resistance genes contained in the cultivars and lines, and several cultivars had durable resistance for the disease (Table 1). Ibis, which possesses multiple resistance genes to YR (1), displayed HR in all 19 years. Atou, Bouquet, Champlein, Flanders, Flinor, Hobbit, Joss Cambier, Little Joss, Longbow, Maris Huntsman, Maris Widgeon, Moulin, Pagode, and Vilmorin 27 were susceptible to one or more races among CYR29, CYR31, and CYR32 but these cultivars and lines had low adult-plant stage MDS (0 to 25\%) during 19 years of testing; Cappelle Desprez had lower MDS (0 to $10 \%$ ) in 18 years and only exhibited a higher MDS of $30 \%$ in 2005; Holdfast had a lower MDS of 0 to $25 \%$ in 18 years and a higher MDS of $45 \%$ in 2005 . These two cultivars still showed APR in the field, indicating that they probably continue to have value if combined with other resistance genes. In contrast, C591, with a single resistance gene, was resistant to YR before 1998 but became susceptible in 1999. Carstens V was resistant to YR, with IT 1 to 2, during 1993 to 1998, then became susceptible in 1999. Vilmorin 23 was resistant to YR during 1993 to 1999 and became susceptible in 2001. The resistances of three cultivars were overcome after spread of the race CYR32, and these cultivars also had high MDS ( 5 to $60 \%$ ).

In order to be confident in the effectiveness and durability of YR resistance, wheat genotypes should be tested under naturally infected and inoculated conditions in the field for a long period. In this study, several cultivars showed HR to MR in the first 4 to 5 years but then gradually became susceptible. For example, C591 was very resistant (IT 0) in 1993 to 1994; we made crosses of C591 and many elite lines were bred but C591 and its derivatives became susceptible after 1999 with the spread of race CYR32.

\section{Acknowledgments}

This study was supported by the National Key Basic Research Program of China (2013CB127700), National Natural Science Foundation of China (31261140370), International Collaboration Projects from the Ministries of Science and Technology (2011DFG32990) and Agriculture (2011-G3), National 863 Project (2012AA101105), and the China Agriculture Research System (CARS-3-1-3). We thank R. A. McIntosh, Plant Breeding Institute, University of Sydney, for critical review of this manuscript.

\section{Literature Cited}

1. Bai, B., Ren, Y., Xia, X. C., Du, J. Y., Zou, G., Wu, L., Zhu, H. Z, He, Z. H. and Wang C. S. 2012. Mapping of quantitative trait loci for adult plant resistance to stripe rust in German wheat cultivar Ibis. J. Integr. Agric. 11:528-536.

2. Bai, Y. L., Sun, Q., Zhang, C. Y., Cui, N., Lin, F., Xu, S. C., Zhang, Z. Y., Gao, Y., and Xu, X. D. 2010. Molecular detection and resistance evaluation of 59 cultivars from the Northwest of the United States to Chinese stripe rust races. Sci. Agric. Sin. 43:1147-1155.

3. Bariana, H. S., and McIntosh, R. A. 1993. Cytogenetic studies in wheat XIV. Location of rust resistance genes in VPM 1 and their genetic linkage with other disease resistance genes in chromosome 2A. Genome 36:476482.

4. Calonnec, A., Johnson, R., and De Vallavieille-Pope, C. 1997. Identification and expression of the gene $\mathrm{Yr} 2$ for resistance to Puccinia striiformis in the wheat differential cultivars Heines Kolben, Heines Peko and Heines VII. Plant Pathol. 46:387-396.

5. Chen, W. Q., Wu, L. R., Liu, T. G., Xu, S. C., Jin, S. L., Peng, Y. L., and Wang, B. T. 2009. Race dynamics, diversity, and virulence revolution in Puccinia striiformis f. sp. tritici, the causal agent of wheat stripe rust in China from 2003 to 2007. Plant Dis. 93:1093-1101.

6. Chen, X. M. 2005. Epidemiology and control of stripe rust (Puccinia striiformis f. sp. tritici) on wheat. Can. J. Plant Pathol. 27:314-337.

7. Chen, X. M., and Line, R. F. 1993. Inheritance of stripe rust resistance in wheat cultivars postulated to have resistance genes at $\mathrm{Yr} 3$ and $\mathrm{Yr} 4$ loci. Phytopathology 83:382-388.

8. Chen, X. M., and Line R. F. 1993. Inheritance of stripe rust (yellow rust) resistance in the wheat cultivar Carstens V. Euphytica 71:107-113.

9. Chen, X. M., Line, R. F., and Jones, S. S. 1995. Chromosomal location of genes for stripe rust in spring wheat cultivars Compair, Fielder, Lee, and Lemhi and interactions of aneuploid wheats with races of Puccinia striiformis. Phytopathology 85:375-381. 
10. Chen, X. M., Line, R. F., Shi, Z. X., and Leung, H. 1998. Genetics of wheat resistance to stripe rust. Pages 237-239 in: Proc. 9th Int. Wheat Genet. Symp. A. E. Slinkard, ed. University Extension Press, University of Saskatchewan, Saskatoon, SK, Canada.

11. Eriksen, L., Afshari, F., Christiansen, M. J., McIntosh, R. A., Jahoor, A., and Wellings, C. R. 2004. Yr32 for resistance to stripe (yellow) rust present in the wheat cultivar Carstens V. Theor. Appl. Genet. 108:567-575.

12. Feng, J., Zhang, Z. Y., Lin, R. M., and Xu, S. C. 2009. Postulation of seedling resistance genes in 20 wheat cultivars to yellow rust (Puccinia striiformis f. sp. tritici). Agric. Sci. China 8:1429-1439.

13. He, Z. H., Lan, C. X., Chen, X. M., Zou, Y. C., Zhuang, Q. S., and Xia, X. C. 2011. Progress and perspective in research of adult-plant resistance to stripe rust and powdery mildew in wheat. Sci. Agric. Sin. 44:2193-2215.

14. Jin, Y. 2011. Role of Berberis spp. as alternate hosts in generating new races of Puccinia graminis and P. striiformis. Euphytica 179:105-108.

15. Keshavarzi, M., Hallajian, T. M., Bagheri, A., and Afshari, F. 2004. Identification of resistance gene(s) to yellow rust in wheat bulked genomic DNAs using RGAP and RAPD marker. In: Int. Cereal Rusts Powdery Mildews Conf. John Innes Centre, Norwich, UK.

16. Law, C. N., and Worland, A. J. 1997. The control of adult plant resistance to yellow rust by the translocated chromosome 5BS-7BS of bread wheat. Plant Breed. 116:59-63.

17. Li, Y., Niu, Y. C., and Chen X. M. 2009. Mapping a stripe rust resistance gene $\operatorname{YrC591}$ in wheat variety C591 with SSR and AFLP markers. Theor. Appl. Genet. 118:339-346.

18. Li, Z. F., Xia, X. C., Zhou, X. C., Niu, Y. C., He, Z. H., Zhang, Y., Li, G. Q., Wan, A. M., Wang, D. S., Chen, X. M., Lu, Q. L., and Singh, R. P. 2006. Seedling and slow rusting resistance to stripe rust in Chinese common wheats. Plant Dis. 90:1302-1312.

19. Li, Z. Q., and Zeng, S. M. 2002. Wheat Rusts in China. China Agriculture Press, Beijing.

20. Liu, T. G., Peng, Y. L., Chen, W. Q., and Zhang Z. Y. 2010. First detection of virulence in Puccinia striiformis f. sp. tritici in China to resistance genes Yr24 (=Yr26) present in wheat cultivar Chuanmai 42. Plant Dis. 94:1163.

21. Lu, Y. M., Lan, C. X., Liang, S. S., Zhou, X. C., Liu, D., Zhou, G., Lu, Q. L., Jing, J. X., Wang, M. N., and Xia, X. C. 2009. QTL mapping for adult-plant resistance to stripe rust in Italian common wheat cultivars Libellula and Strampelli. Theor. Appl. Genet. 119:1349-1359.

22. Lupton, F. G. H., and Macer, R. C. F. 1962. Inheritance of resistance to yellow rust (Puccinia glumarum Erikss. and Henn.) in seven varieties of wheat. Trans. Br. Mycol. Soc. 45:21-45.

23. Macer, R. C. F. 1966. The formal and monosomic genetic analysis of stripe rust (Puccinia striiformis) resistance in wheat. Pages 127-142 in Proc. 2nd Int. Wheat Genet. Symp. J. MacKey, ed. Hereditas, Lund, Sweden.

24. Macer, R. C. F. 1975. Plant pathology in a changing world. Trans. Br. Mycol. Soc. 65:351-374
25. McIntosh, R. A., Dubcovsky, J., Rogers, W. J., Morris, C. F., Appels, R. and Xia, X. C. 2012. Catalogue of gene symbols for wheat: 2012 supplement. Online publication. http://www.shigen.nig.ac.jp/wheat/komugi/genes/ macgene/supplement2012.pdf

26. McIntosh, R. A., Wellings, C. R., and Park, R. F. 1995. Wheat Rusts: An Atlas of Resistance Genes. Commonwealth Scientific and Industrial Research Organisation (CSIRO), East Melbourne, Victoria, Australia.

27. McIntosh, R. A., Yamazaki. Y., Devos, K. M., Dubcovsky. J., Rogers, J., and Appels, R. 2003. Catalogue of gene symbols for wheat. Pages 31-40 in: 10th Int. Wheat Genet. Symp. Paestum, Italy

28. Peterson, R. F., Campbell, A. B., and Hannah, A. E. 1948. A diagrammatic scale for estimating rust intensity on leaves and stems of cereals. Can. J. Res. Sect. C. 26:496-500.

29. Riley, R., Chapman, V., and Johnson, R. 1968. The incorporation of alien disease resistance in wheat by genetic interference with the regulation of meiotic chromosome synapsis. Genet. Res. Camb. 12:713-715.

30. Singh, D., Park, R. F., McIntosh, R. A., and Bariana, H. S. 2008. Characterisation of stem rust and stripe rust seedling resistance genes in selected wheat cultivars from the United Kingdom. J. Plant Pathol. 90:553-562.

31. Singh, R. P., Huerta-Espino, J., and Rajaram, S. 2000. Achieving nearimmunity to leaf and stripe rusts in wheat by combining slow rusting resistance genes. Acta Phytopathol. Entomol. Hung. 35:133-139.

32. Wan, A. M., Chen, X. M., and He, Z. H. 2007. Wheat stripe rust in China. Aust. J. Agric. Res. 58:605-619.

33. Wan, A. M., Zhao, Z. H., Chen, X. M., He, Z. H., Jin, S. L., Jia, Q. Z., Yao, G., Yang, J. X., Wang, B. T., Li, G. B., Bi, Y. Q., and Yuan, Z. Y. 2004 Wheat stripe rust epidemic and virulence of Puccinia striiformis f. sp. tritici. Plant Dis. 88:896-904.

34. Wang, L. F., Ma, J. X., Zhou, R. H., Wang, X. M., and Jia, J. Z. 2002. Molecular tagging of the yellow rust resistance gene $\mathrm{YrlO}$ in common wheat P.I.178383 (Triticum aestivum L.). Euphytica 124:71-73.

35. Worland, A. J., and Law, C. N. 1986. Genetic analysis of chromosome 2D of wheat. Z. Pflanzenzuecht. 96:331-345.

36. Zeng, S. M., and Luo, Y. 2006. Long-distance spread and interregional epidemics of wheat stripe rust in China. Plant Dis. 90:980-988.

37. Zhang, J. Z., Lin, R. M., Cao, L. H., He, Y. Q., and Xu, S. C. 2007. Monosomic analysis of the wheat stripe rust resistant genes in Taichung29*6/Strubes Dickkopf. Acta Phytophylac. Sin. 34:343-346.

38. Zhao, J., Wang, L., Wang, Z. Y., Chen, X. M., Zhang, H. C., Yao, J. N., Zhan, G. M., Chen, W., Huang, L. L., and Kang Z. S. 2013. Identification of eighteen Berberis species as alternate hosts of Puccinia striiformis $\mathrm{f}$. $\mathrm{sp}$ tritici and virulence variation in the pathogen isolates from natural infection of Barberry plants in China. Phytopathology 103:927-934.

39. Zhou, X. C., Wu, L. R., Song, J. R., and Jin, S. L. 2008. Control of wheat stripe rust based on genetic diversity of cultivars in Longnan. Acta Phytophylac. Sin. 35:97-101. 